\title{
River runoff reconstructions from novel spectral luminescence scanning of massive coral skeletons
}

\author{
C. A. Grove $\cdot$ R. Nagtegaal $\cdot$ J. Zinke $\cdot$ T. Scheufen $\cdot$ \\ B. Koster $\cdot$ S. Kasper $\cdot$ M. T. McCulloch • \\ G. van den Bergh · G. Jan A. Brummer
}

Received: 25 November 2009/ Accepted: 25 April 2010/Published online: 15 May 2010

(C) The Author(s) 2010. This article is published with open access at Springerlink.com

\begin{abstract}
Inshore massive corals often display bright luminescent lines that have been linked to river flood plumes into coastal catchments and hence have the potential to provide a long-term record of hinterland precipitation. Coral luminescence is thought to result from the incorporation of soil-derived humic acids transported to the reef during major flood events. Corals far from terrestrial sources generally only exhibit dull relatively broad luminescence bands, which are attributed to seasonal changes in coral density. We therefore tested the hypothesis that spectral ratios rather than conventional luminescence intensity provide a quantitative proxy record of river runoff without the confounding effects of seasonal density chan-
\end{abstract}

Communicated by Geology Editor Dr. Bernhard Riegl

Electronic supplementary material The online version of this article (doi:10.1007/s00338-010-0629-y) contains supplementary material, which is available to authorized users.

C. A. Grove $(\bowtie) \cdot$ R. Nagtegaal · J. Zinke · T. Scheufen ·

S. Kasper · G. J. A. Brummer

Department of Marine Geology, Royal Netherlands Institute

for Sea Research (NIOZ), P.O. Box 59, 1790 AB Den Burg,

Texel, The Netherlands

e-mail: craig.grove@nioz.nl

J. Zinke

Department FALW, Vrije Universiteit Amsterdam, De

Boelelaan 1105, $1081 \mathrm{HV}$ Amsterdam, The Netherlands

T. Scheufen

Institute for Biodiversity and Ecosystem Dynamics (IBED),

University of Amsterdam, Nieuwe Achtergracht 127,

1018 WS Amsterdam, The Netherlands

B. Koster

Department of Marine Technology Electronics, Royal

Netherlands Institute for Sea Research, P.O. Box 59,

1790 AB Den Burg, Texel, The Netherlands ges. For this purpose, we have developed a new, rapid spectral luminescence scanning (SLS) technique that splits emission intensities into red, green and blue domains (RGB) for entire cores with an unprecedented linear resolution of $71.4 \mu \mathrm{m}$. Since humic acids have longer emission wavelength than the coral aragonite, normalisation of spectral emissions should yield a sensitive optical humic acid/aragonite ratio for humic acid runoff, i.e., G/B ratio. Indeed, $\mathrm{G} / \mathrm{B}$ ratios rather than intensities are well correlated with $\mathrm{Ba} / \mathrm{Ca}$, a geochemical coral proxy for sediment runoff, and with rainfall data, as exemplified for coral records from Madagascar. Coral cores also display recent declining trends in luminescence intensity, which are also reported in corals elsewhere. Such trends appear to be associated with a modern decline in skeletal densities. By contrast, G/B spectral ratios not only mark the impact of individual cyclones but also imply that humic acid runoff

S. Kasper

Geologisches Institut, Wüllnerstrasse 2, 52056 RWTH Aachen, Germany

M. T. McCulloch

Research School of Earth Sciences \& ARC Coral Reef Centre of Excellence, Australian National University, Mills Road, Canberra 0200, Australia

M. T. McCulloch

ARC Centre of Excellence in Coral Reef Studies, University of Western Australia, School of Earth and Environment, M004, Crawley, WA 6009, Australia

G. van den Bergh

University of Wollongong, SEES, Wollongong, NSW 2522,

Australia 
increased in Madagascar over the past few decades while coral skeletal densities decreased. Consequently, the SLS technique deconvolves the long-term interplay between humic acid incorporation and coral density that have confounded earlier attempts to use luminescence intensities as a proxy for river runoff.

Keywords Luminescence spectra - Soil runoff . Coral carbonate $\cdot$ Humic acids $\cdot$ Core scanning

\section{Introduction}

Understanding the impact of global warming on presentday rainfall patterns and river discharge requires constraints on long-term 'natural' climate variability and hence the need for climate records extending back for at least several hundred of years. Unfortunately such records are rare, and in some locations such as Madagascar, even present-day weather data remains scarce (Dewar and Wallis 1999; Dewar and Richard 2007). This lack of continuous long-term instrumental data highlights the importance of climate proxy records such as those preserved in the massive annually banded coral Porites sp. (McCulloch et al. 1994; Felis and Pätzold 2003; Lough 2004; Grottoli and Eakin 2007 and references therein). Various skeletal properties have been employed to trace past climate change using coral records, yet their ability to be used as environmental proxies is compromised by our limited mechanistic understanding of their origin (Lough 2004; Corrège 2006; Jones et al. 2009 and references therein).

When placed under ultraviolet (UV) light, some coral cores show bright luminescence patterns that are related to freshwater flood events and thus past river flow and rainfall dynamics in tropical environments (Isdale 1984; Boto and Isdale 1985; Scoffin et al. 1989; Lough et al. 2002). Pioneered by Isdale (1984), a number of techniques have been developed to measure the varying intensity of luminescence in coral skeletons (Barnes et al. 2003 and references therein; electronic supplemental material, ESM). Variability in emission intensities was first thought to be caused by the incorporation of luminescent humic acids and soil-derived organic compounds introduced by seasonal river runoff (Isdale 1984; Susic and Boto 1989; Susic et al. 1991; Matthews et al. 1996; Isdale et al. 1998; Wild et al. 2000). Changing coral density and architecture has been proposed as another cause since massive corals form a skeleton of luminescent aragonite (MacRae and Wilson 2008), and banded luminescence is also found in corals in oceanic environments devoid of terrestrial inputs (Barnes and Taylor 2001a, b). Barnes and Taylor (2005) introduced a classification of skeletal luminescence patterns discriminating between faint bands and bright lines. Faint luminescent banding is attributed to the annual skeletal density banding, while the brighter narrow luminescent lines (linked to runoff) are considered to be associated with another component, e.g., humic acids, relating to skeletal chemistry (Barnes and Taylor 2005). Therefore, the hypotheses formulated for this research paper are (1) both humic acids and aragonite density determine luminescence intensities in corals and (2) that their deconvolution is required in order to reconstruct river runoff accurately.

This study introduces a novel scanning technique that quantifies luminescence intensities by splitting the total emission spectrum into different spectral domains. Measured luminescence intensities and calculated spectral luminescence ratios are analysed from coral cores drilled in Madagascar to investigate the potential for normalising the episodic bright (humic acid) emission bands to the overall aragonite skeleton emission, thus generating normalised luminescence data using spectral luminescence ratios. Recently, Cobb et al. (2008) addressed various sources of uncertainties in coral luminescence-based paleorecords. Firstly, the cause of luminescence in corals is not fully understood (Barnes and Taylor 2001a, 2005; Jones et al. 2009), and secondly, there is some evidence that luminescence intensities show an unexplained long-term declining trend that could compromise runoff reconstructions (Isdale et al. 1998; Lough JM pers comm). The aim of this research is to improve the robustness of luminescence as a proxy for humic acid runoff, while resolving the uncertainties addressed by Cobb et al. (2008).

While banded luminescence seems to reflect the organic flux carried by seasonal variability in river runoff (Isdale 1984), coral $\mathrm{Ba} / \mathrm{Ca}$ also provides a highly sensitive tracer of suspended sediment fluxes (Alibert et al. 2003; McCulloch et al. 2003) and in some regions, upwelling (Fallon et al. 1999). Suspended sediments (clays) carry adsorbed barium and other river-born trace elements that are desorbed in the low-salinity estuarine mixing zone and subsequently behave as conservative dissolved constituents of the ambient seawater in which the corals thrive (Sinclair and McCulloch 2004). Consequently, Ba/Ca and luminescence are used to reconstruct sediment and humic acid runoff, respectively in tropical catchments, where both have been shown to co-vary with the changing magnitude of precipitation and river flow (Fleitmann et al. 2007). As Madagascar weather data are scarce (Dewar and Wallis 1999; Dewar and Richard 2007), novel spectral luminescence ratios and conventional luminescence intensities are paired with $\mathrm{Ba} / \mathrm{Ca}$ to validate the method, supported by rainfall data from a nearby weather station. Finally, differences in luminescence between corals from reef environments near and distant from terrestrial inputs will be evaluated. 


\section{Materials and methods}

Spectral luminescence scanning (SLS) was developed to quantify skeletal emissions in different spectral domains from coral cores (Grove et al. 2009). Below, we describe how spectral emission intensities are quantified for entire core slabs and the modifications undertaken of the Avaatech core-scanner, conventionally used for analysing the changing element composition of entire sediment cores by X-ray fluorescence (Jansen et al. 1998; Richter et al. 2006). The Avaatech XRF core-scanner is equipped with a linescan camera that yields high-resolution images using visible light to establish digital core archives and to assist in interpreting element stratigraphy data. It is the line-scan camera in combination with the core-scanning technology that makes this technique unique. A summary of the techniques advantages can be found in the electronic supplementary material (ESM) together with a detailed description of the method.

\section{Method summary}

The standard light source of the Avaatech core-scanner was replaced by two long-wave UV-A tubes in the $350-450 \mathrm{~nm}$ range (Fig. 1). The light source and camera progress down the sample slab as a single unit when the scan is initiated, constantly scanning multiple lines, resulting in a continuous core image. A 450-nm light cut-off filter is optionally placed beneath the camera lens to eliminate reflected light from the UV source and record luminescence intensities in the blue domain (Fig. 1). Luminescence emission is recorded by a Line Scan Camera. Incoming light passing through the lens is split into three wavelength ranges (Red, Green and Blue) by a Dichroic RGB beam splitter prism and recorded by separate sensors (Fig. 1). As the camera moves over the slab, it continuously collects a single crosscore line image of $2048 \times 1$ pixels for each spectral range. The current set-up gives a spatial resolution of 140 pixels per $\mathrm{cm}$, each pixel therefore yielding a linear resolution of $71.4 \mu \mathrm{m}$. Three data points are produced for each individual pixel in the $R, G$ and $B$ range.

The specifically designed software (Avaatech) enables linear transects to be manually drawn from the luminescence image to retrieve intensity profiles for any specified area and direction (Fig. 2). Once the areas of interest are identified, transects are created up to $150 \mathrm{~cm}$ in length and $15 \mathrm{~cm}$ in width, however, usually limited to shorter transects depending on sample size, changes in the direction of growth axes or breaks and/or visual discrepancies in the sample. Connecting transects is achieved by transferring quantified intensity data into a separate program used for data management. Multiple transects can be created for any length, in any direction, at any required width from just a
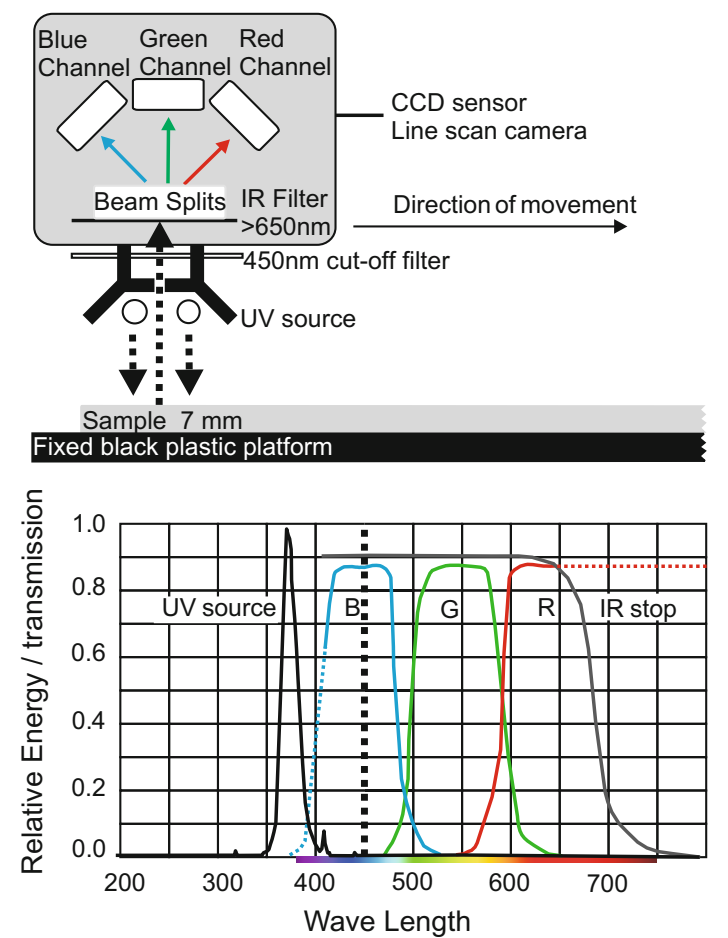

Fig. 1 Schematic diagram of the modified Avaatech core-scanner used for spectral luminescence imaging (upper panel) and the spectral distribution and sensitivity of the light source and camera sensors (lower panel). The UV light source efficiently emits in the range of $315-450 \mathrm{~nm}$. The 450-nm cut-off filter (black dotted line) removes all UV source emissions (reflected light) before splitting into red, green and blue fractions by a dichroic RGB beam splitter. A 650-nm infrared cut-off filter prevents light of greater wavelengths from entering the three separate CCD sensors

single scan taking up to $1 \mathrm{~h}$. Uranyl glass with homogenous luminescent properties is mounted on the platform and used as a standard reference for all intensity measurements. Line transects drawn through the entire length of the standard material using the image and software are used to correct for any drift in either the light source intensity or camera recording sensitivity. Subsequently, the resulting sample intensities are corrected for any drift to allow direct inter-comparisons between cores to be made over time. Importantly, SLS provides fast, non-destructive quantified data that allows for matching and comparing coral carbonate skeletons with little sampling effort.

Core collection and sample preparation

A total of five coral cores drilled from Porites sp. colonies, four from Antongil Bay (E 49, $\mathrm{S} 15^{\circ}$ ) and one off St Marie island (E $49^{\circ}, \mathrm{S} 17^{\circ}$ ), Northeast Madagascar (Fig. 3), were used to test this new technique, with a more detailed coral climate analysis being given elsewhere. The four cores from Antongil Bay are all influenced by seasonal river plumes occurring in the wet season between December and 


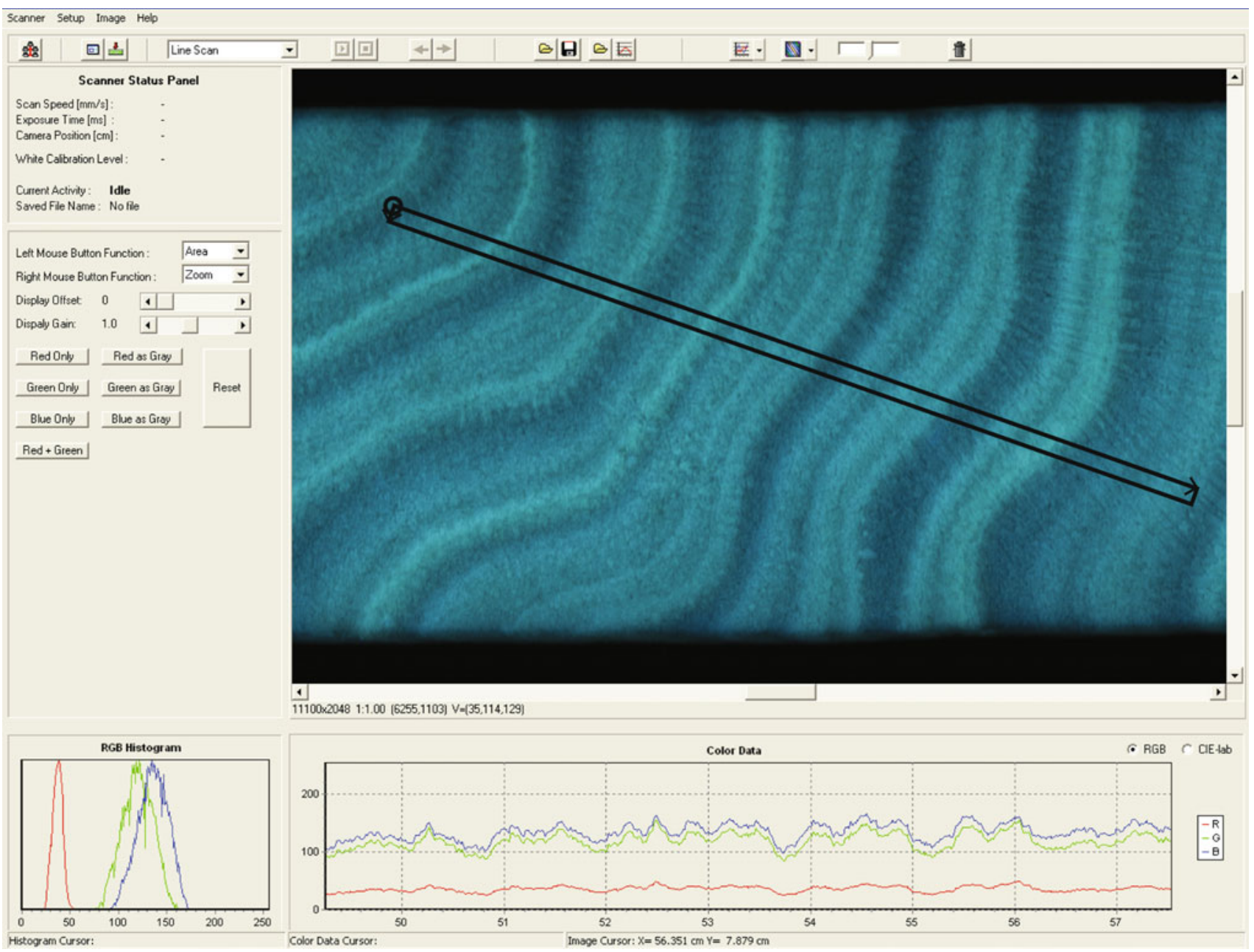

Fig. 2 Screen shot of the software used to analyse UV luminescence imaging. The image shows a section of the coral core ANDRA, with a black transect drawn onto the image parallel to the growth axis.

April. The other core from St Marie is not influenced by any river. All cores were collected in March and April 2007 between the depth ranges of 4-6 $\mathrm{m}$ and are dated between 27- and 129-years-old (Table 1). A detailed description of the research area and climate setting is provided in the ESM. Coral chronologies were developed by counting density bands using digitalised X-rays, complemented by counting luminescence intensity bands (Hendy et al. 2003).

All coral cores were cut into 7-mm-thick slabs and ultrasoniced three times in ultrapure $17 \Omega$ water for 10 -min periods, removing all surficial particles. For luminescence measurements, coral slabs must have a smooth surface and be of uniform thickness. The slabs were also cleaned with compressed filtered air between ultrasonicing to remove all remaining loose particles and dried for $24 \mathrm{~h}$ in a laminar flow hood. It is essential to clean cores identically in order to prevent changes in emissions through the addition or removal of luminescent substances between cores
Multiple transects can be manually selected on the digital image in any direction for any width after a single scan

(Carricart-Ganivet et al. 2007). Particularly for the most recent years, intensities decrease due to the quenching signal by residual organic matter associated with the coral tissue layer and/or endolithic algae. Oxidative cleaning for $24 \mathrm{~h}$ with sodium hypochlorite $(\mathrm{NaOCl}, 10-13 \%$ reactive chloride; Sigma-Aldrich Company, St. Louis, MO) removes these contaminating organics yet may also affect the chemistry of the skeletal lattice compromising climate reconstruction (Boiseau and Juillet-Leclerc 1997; Watanabe et al. 2001; Grottoli et al. 2005). Therefore, cores were first sampled for geochemical analysis and then scanned for spectral luminescence before and after treatment with $\mathrm{NaOCl}$.

Luminescence intensities generated by the SLS technique were also compared to the emission produced using an argon-ion laser-beam as an excitation source and an Ocean-Optics linear diode array detector via an optical fibre at the VU University, Amsterdam. Laser-Ablation ICP-MS profiles were undertaken to determine $\mathrm{Ba} / \mathrm{Ca}$ 


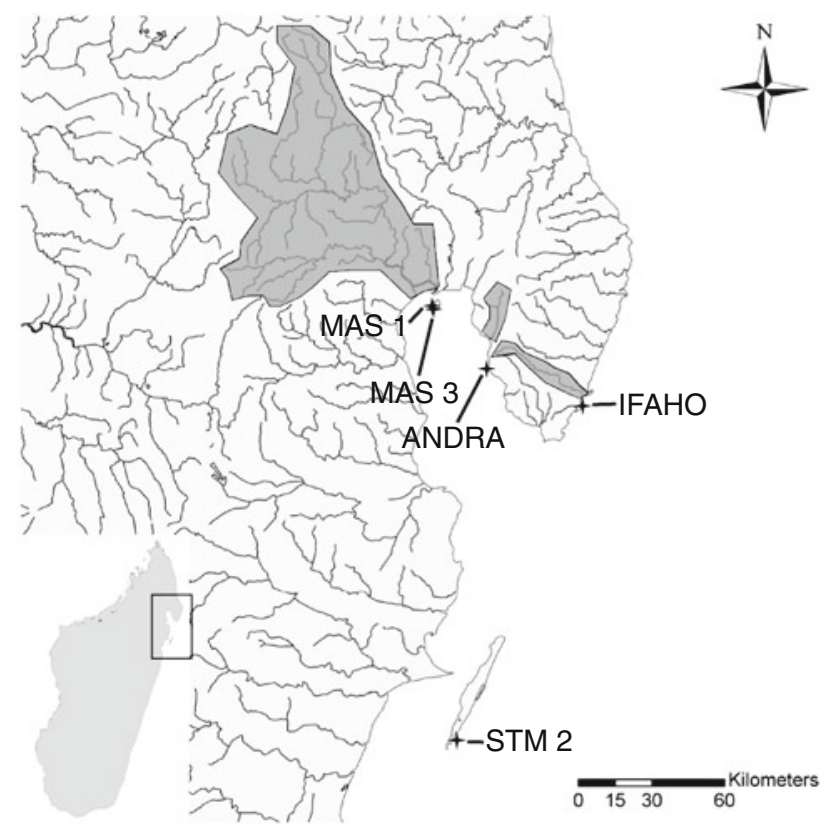

Fig. 3 Map of the region where cores MAS1, MAS3, ANDRA, IFAHO and STM2 were drilled. Coral locations (stars) and their corresponding rivers and watersheds (grey shaded areas) are marked accordingly in and around Antongil Bay. The largest river is the Antainambalana, influencing MAS1 and MAS3; the river influencing ANDRA is the Ambanizana, flowing south westward into the bay; and the river influencing IFAHO is the Anaovandran flowing eastward outside the bay. The coral core STM2 is not influenced by any river and is located to the south east of the island St Marie

ratios at a sub-weekly resolution on the coral core MAS1 at ANU Canberra following the method of Sinclair et al. (1998) and Fallon et al. (2002). Geochemical analysis yielded $\mathrm{Ba} / \mathrm{Ca}$ ratios, a well-established proxy for sediment runoff, used here to cross-validate the luminescence results (McCulloch et al. 2003). Density profiles were measured using the CoralXDS program, where X-ray images were digitalised, uploaded and calibrated using an aragonite wedge (Helmle et al. 2002; Carricart-Ganivet et al. 2007).
Rainfall and river discharge time series are not available for Antongil Bay and are generally scarce across Madagascar (Kremen 2003). However, for calibration of coral luminescence data, we use Tamatave (WMO code 67095), the nearest weather station with rainfall data $\left(18.15^{\circ} \mathrm{S}\right.$, $\left.49.37^{\circ} \mathrm{E}\right), 293 \mathrm{~km}$ south of Antongil Bay, which also provides the most continuous time series for northeast Madagascar covering the period 1889-1985 (data available at http://www.ncdc.noaa.gov/oa/climate/ghcn-monthly/).

\section{Results}

Technique and resolution

Line-scanning achieves a linear resolution of $71.4 \mu \mathrm{m}$, generating detailed luminescence intensity profiles of coral skeletons. This equates to a temporal resolution of 2.6 days for corals growing at a rate of $1 \mathrm{~cm} /$ year. The resolutions achieved by SLS are among the highest found in coral proxy analysis and comparable to Laser-Ablation ICP-MS, used for element composition in palaeo-reconstructions (Sinclair et al. 1998; Fallon et al. 2002). The performance of the new SLS technique was also compared to that obtained from an argon laser excitation, coupled with a linear diode array detector via an optical fibre (Milne and Swart 1994). Intensity profiles appear very similar for both methods, considering the lower linear resolution of $0.1 \mathrm{~mm}$ achieved with the laser method (Fig. ESM1).

\section{Coral luminescence intensities}

Digital images generated using visual and UV light are displayed for the top section of the MAS1 coral core, a 15.8-cm slab covering the years 1991-2006 (Fig. 4). Luminescence scanning displayed seasonal variability in relative intensities, with a gradual decline observed since

Table 1 A summary of the five coral cores drilled in Madagascar, applied in a manner that demonstrates the potential of the SLS technique and the application of spectral luminescence ratios. In some cases, only sections of cores were used for this study

\begin{tabular}{|c|c|c|c|c|c|}
\hline Coral name & Location & Length $(\mathrm{cm})$ & Age (years) & $\begin{array}{l}\text { Distance to closest } \\
\text { river source }(\mathrm{km})\end{array}$ & $\begin{array}{l}\text { Average growth } \\
\text { rate }(\mathrm{cm} / \mathrm{yr})\end{array}$ \\
\hline MAS1 (Antongil Bay) & $\begin{array}{l}\text { S } 15^{\circ} 30,566 \\
\text { E } 49^{\circ} 45,437\end{array}$ & 120.78 & 102 & 7 & 1.18 \\
\hline MAS3 (Antongil Bay) & $\begin{array}{l}\text { S } 15^{\circ} 30,578 \\
\text { E } 49^{\circ} 45,456\end{array}$ & 142.97 & 129 & 7 & 1.11 \\
\hline ANDRA (Antongil Bay) & $\begin{array}{l}\text { S } 15^{\circ} 41,17 \\
\text { E } 49^{\circ} 57,419\end{array}$ & 119.82 & 94 & 7 & 1.27 \\
\hline IFAHO (Antongil Bay) & $\begin{array}{l}\text { S } 15^{\circ} 51,968 \\
\text { E } 50^{\circ} 18,73\end{array}$ & 37.95 & 27 & 4.5 & 1.41 \\
\hline STM2 (St Marie) & $\begin{array}{l}\text { S } 17^{\circ} 05,685 \\
\text { E } 49^{\circ} 51,483\end{array}$ & 168 & 115 & 40 & 1.45 \\
\hline
\end{tabular}




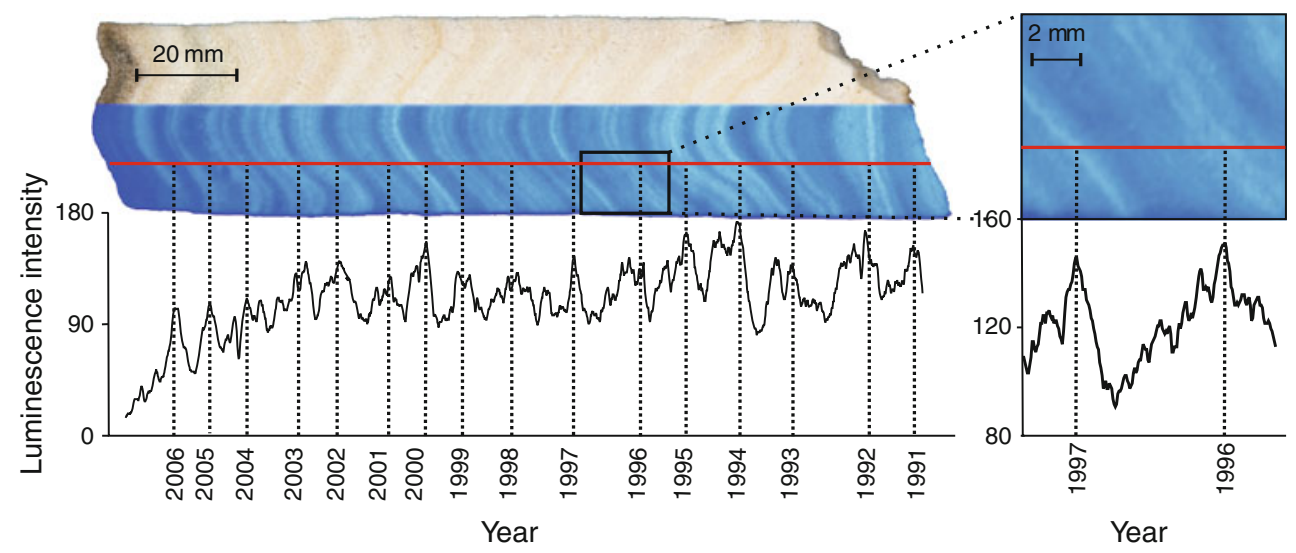

Fig. 4 An example of the digital images generated by the line-scan camera using the top section of the coral core MAS1, scanned under visible light (top half) and UV light (bottom half). The red transect line marks the area of which green luminescence intensity $(G)$ is measured, with annual cycles assigned to the raw data by designating

2003 (Fig. 4). Treated with $\mathrm{NaOCl}$, the intensity of luminescence for the most recent bands increases (Fig. ESM2). MAS1 shows periodic yellow bands within the skeleton under visual light that correlate temporally with increased luminescence intensities (Fig. 4). As illustrated for the years 1996 and 1997, high magnification of the digital image improves the ability to identify and avoid physical discrepancies within cores and enables the precise selection of sampling tracks (Fig. 4).

Luminescence assists with the construction of age models by analysing the green luminescence intensity profiles, exemplified for a 9-year section of each core drilled within Antongil Bay (Fig. 4). In addition to counting annual bands down-core, there are singular sections within the profiles that each displays a distinct pattern shared by all corals (Fig. 5). These provide reference points independent of the annual banding leading to robust age models. As expected, the most similar intensity profiles were found for the two nearby cores influenced by the same watershed (MAS1 and MAS3; Figs. 3, 5). For the complete monthly intensity time series, correlations of MAS1 with MAS3 $(R=0.65, P<0.001, n=1,234)$ are higher than with ANDRA $(R=0.63, P<0.001, n=1,112)$ and IFAHO $(R=0.52, P<0.001, n=305)$.

\section{Application of spectral luminescence ratios}

In all cores from Antongil Bay, intensity values in the green domain $(\mathrm{G})$ were higher than in the red $(R)$, whereas the green and blue (B) intensities were similar with the 450-nm filter fixed below the camera (Fig. ESM3). To validate luminescence as a proxy for river runoff, we first correlated luminescence intensity (hereafter $\mathrm{G}$ ) with $\mathrm{Ba} / \mathrm{Ca}$ ratios, an established proxy for sediment runoff (McCulloch et al. peak values from 1991 to 2006. The black box marks an enlarged section of relative photoluminescent intensities (G) for the years 1996 and 1997 (right). A separate transect of a smaller size was created on the zoomed image (red), identifying fine-scaled fluctuations in intensities

2003). Although temporally aligned, there is little agreement between $\mathrm{G}$ and $\mathrm{Ba} / \mathrm{Ca}$ in terms of seasonal amplitudes and the long-term trend (Fig. 6). Spectral ratios are applied to optically remove the assumed density and architectural effect and to retrieve the luminescence signal emitted by the humic acids incorporated from soil runoff (Fig. 6b). As the spectral emissions of humic acids and aragonite cluster at similar wavelengths, it is difficult to separate the two using traditional fluorescence spectroscopy (Matthews et al. 1996; Wild et al. 2000). Although both are within the green-blue range, humic acid emission wavelengths are slightly longer towards the green end of the spectrum (Ramseyer et al. 1997). Hence, the green/blue (G/B) spectral ratio is a measure of the humic acid concentration relative to the aragonite density of the coral.

Correlations of $\mathrm{Ba} / \mathrm{Ca}$ with the spectral $\mathrm{G} / \mathrm{B}$ ratio improve compared to $\mathrm{G}$, exemplified by core MAS1 (Fig. 6b). A marked peak in G/B ratios not observed in G now appears, matching a significant spike in $\mathrm{Ba} / \mathrm{Ca}$ for the year 2000 (Fig. 6b). Indeed, for the total length of the MAS1 core, correlations of $\mathrm{G} / \mathrm{B}$ ratios with $\mathrm{Ba} / \mathrm{Ca}$ are higher and statistically significant $(R=0.60, P<0.001$, $n=1,234)$ compared to $\mathrm{G}$ alone $(R=0.09, P<0.005$, $n=1,234)$. For yearly averages, correlations between $\mathrm{G} / \mathrm{B}$ ratios and $\mathrm{Ba} / \mathrm{Ca}$ remain robust $(R=0.61, P<0.001$, $n=102)$, whereas $\mathrm{G}$ and $\mathrm{Ba} / \mathrm{Ca}$ are negatively correlated (R $=-0.42, P<0.001, n=102$; Fig. 7). Correlations of monthly MAS1 G/B with MAS3 $(R=0.69, P<0.001$, $n=1,234)$ are higher than with ANDRA $(R=0.67$, $P<0.001, n=1,112)$ and IFAHO $(R=0.64, P<0.001$, $n=305$ ). Indeed, correlations of $\mathrm{G} / \mathrm{B}$ between all cores relative to MAS1 are now similar in contrast to $\mathrm{G}$, testifying that $\mathrm{G} / \mathrm{B}$ identifies an environmental signal of regional significance. 


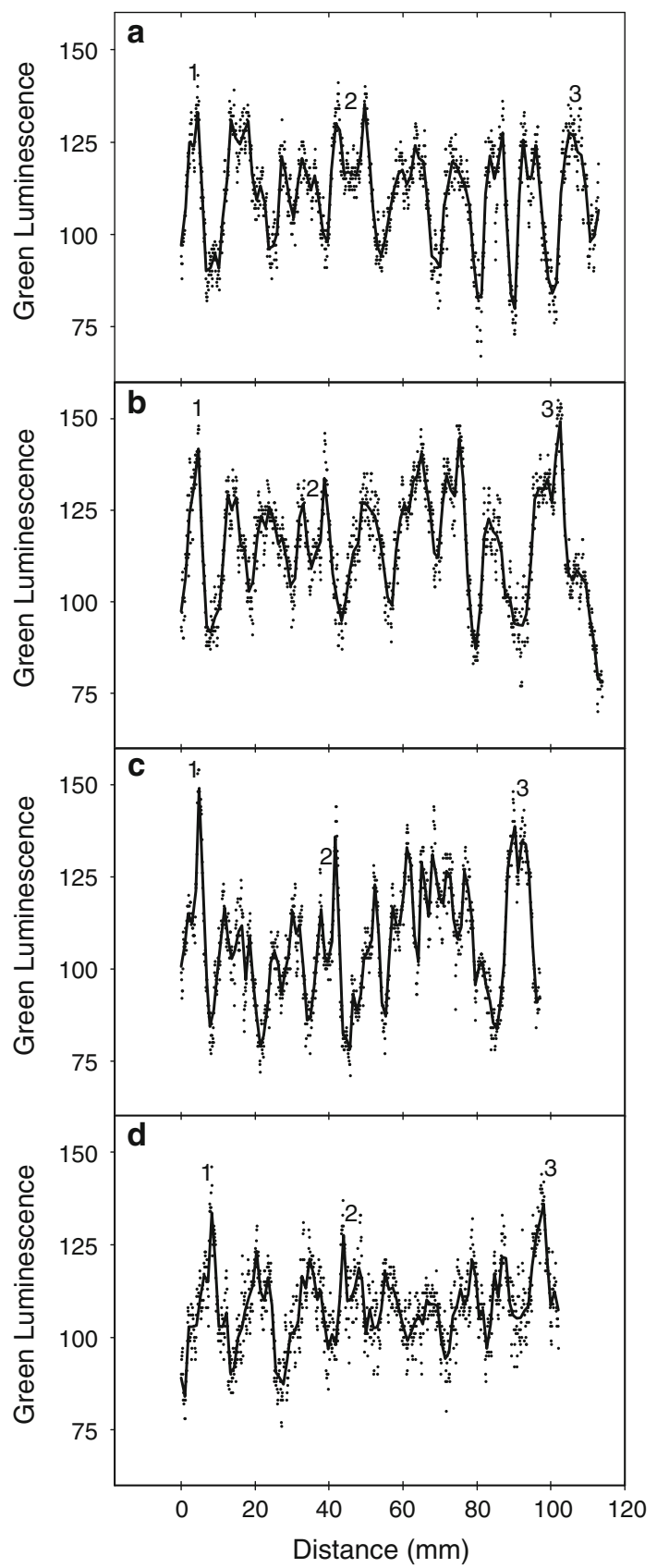

Fig. 5 A 14-point moving average (solid) applied to the raw (dots) luminescence intensity profile data in the green spectral domain $(\mathrm{G})$ for 9-year sections of the Antongil Bay cores MAS1 (a), MAS3 (b), ANDRA (c) and IFAHO (d). Points 1 and 3 mark exceptionally high luminescence intensities, and point 2 a clear double spike within a yearly cycle. MAS1 (a) and MAS3 (b) are located closest to each other $(<1 \mathrm{~km})$ and show the most observed similarities. ANDRA (c) is $30 \mathrm{~km}$ from both MAS1 and MAS3, and IFAHO (d) is a further $40 \mathrm{~km}$ away

In order to further assess the effect of density and architecture on luminescence, samples were manually crushed from the same section of the MAS1 core. Crushing removed the large-scale architecture and was achieved by

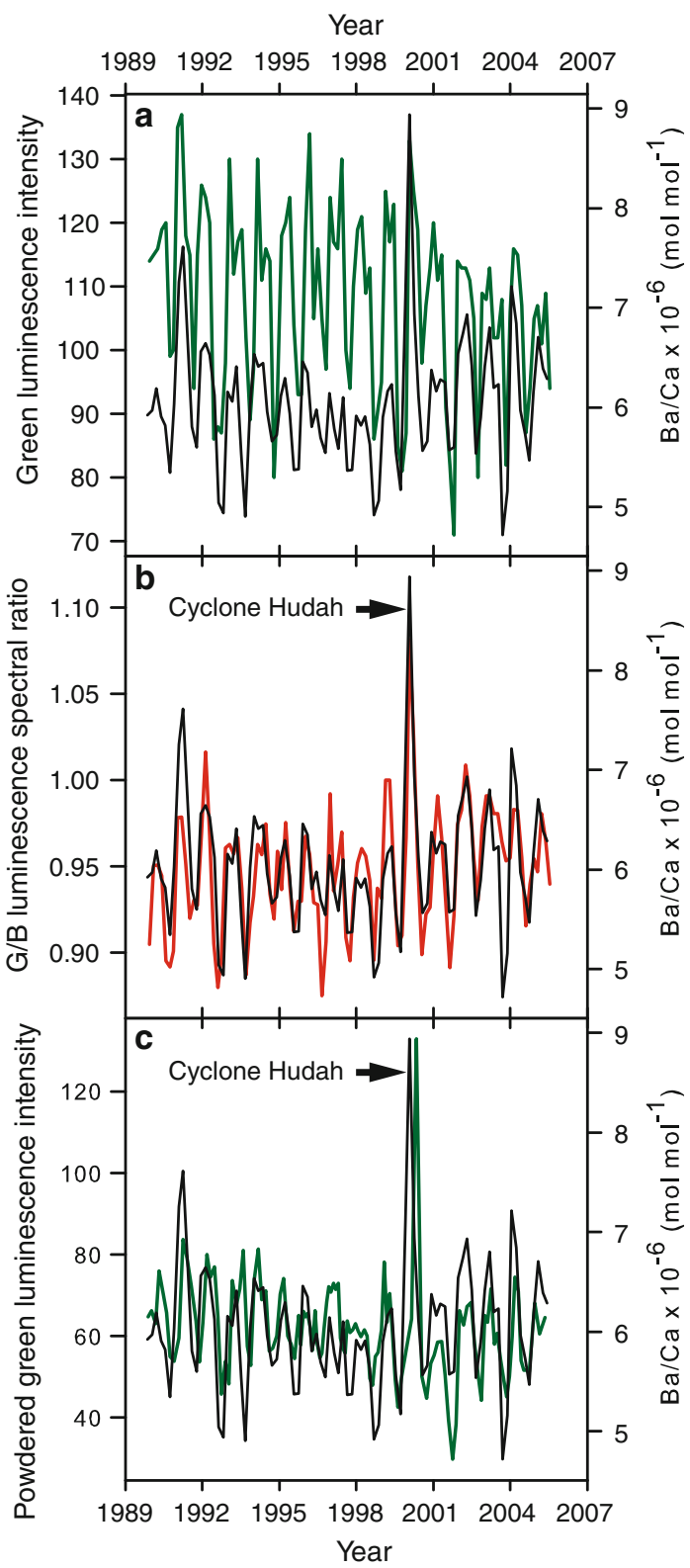

Fig. 6 MAS1 monthly resolved $\mathrm{Ba} / \mathrm{Ca}$ (black) compared with a the monthly averaged $\mathrm{G}$ (green) and $\mathbf{b}$ the $\mathrm{G} / \mathrm{B}$ ratio (red). While the variability in green luminescence and $\mathrm{Ba} / \mathrm{Ca}$-runoff $(\mathbf{a})$ is aligned, seasonal amplitudes and long-term trends are in poor agreement with each other. The correlation coefficient of $\mathrm{G} / \mathrm{B}$ improves with $\mathrm{Ba} / \mathrm{Ca}$ $(R=0.69, P<0.001, n=185 ; \quad$ b $)$ compared to $\mathrm{G}(R=0.5$, $P<0.001, n=185 ;$ a), revealing a significant spike in the year 2000 corresponding to cyclone Hudah. To physically remove architectural effects, monthly sections of the coral sampling transect were powdered and compressed into micro-pellets (c). Green luminescence intensities (green) of micro-pellets also show an observed coherence with $\mathrm{Ba} / \mathrm{Ca}$ (black), including the 2000 spike, testifying to the effect of skeletal architecture on absolute luminescence

drilling sub-samples along the coral growth axis parallel to the optical measurement track, homogenising the extracted powder and pressing them into pellets. Each pellet 

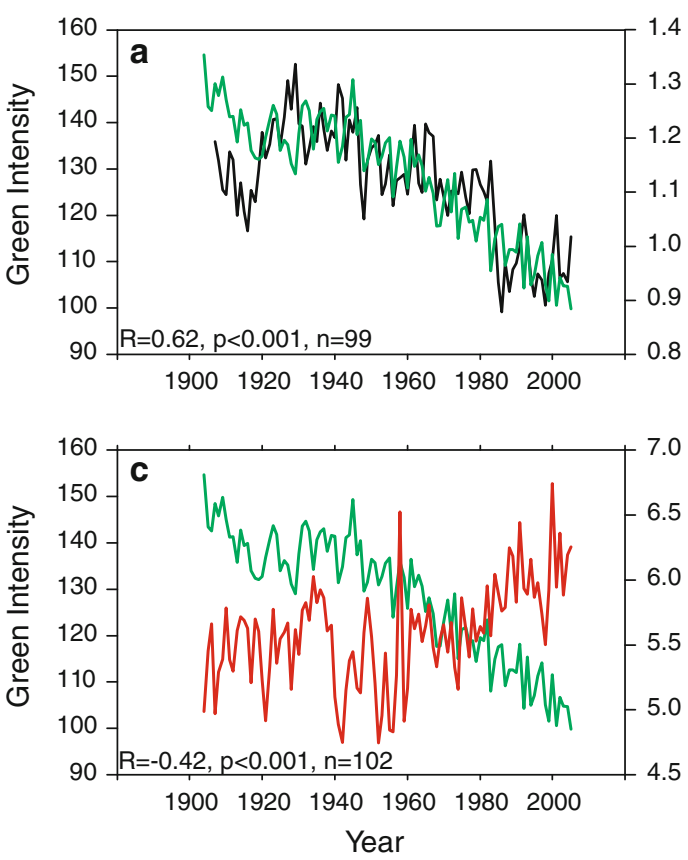

Fig. 7 Time series plots for the annual means of MAS1 G (green), density (black), $\mathrm{Ba} / \mathrm{Ca}($ Red) and $\mathrm{G} / \mathrm{B}$ (Blue). The last 3 years of the $\mathrm{X}$-ray image were distorted and were not used, therefore $n=99$. All parameters were scaled by calculating yearly averages. Correlation coefficients and significance levels are shown at the bottom of each

approximately represented 1 month and was measured using the same SLS technique. Difference in resolution between the crushed samples and scanned cores hinders the perfect alignment of the two time series (Fig. 6c). Nevertheless, crushed sample luminescence intensities show a much improved coherence with $\mathrm{Ba} / \mathrm{Ca}$ (Fig. 6c), as, e.g., the marked peak of 2000 becomes apparent. Consequently, manual crushing confirms that $\mathrm{G} / \mathrm{B}$ spectral ratios effectively normalise the humic acid signal to the aragonite signal in a manner conceptually similar to normalising elemental proxy concentrations against aragonite, i.e., $\mathrm{Ba} / \mathrm{Ca}, \mathrm{Sr} / \mathrm{Ca}$. This provides the opportunity for tracing humic acid runoff in coral records without interference from density and architectural effects.

Coral STM2, from a reef devoid of terrestrial influences, typically shows very low luminescence intensities in the green domain, as exemplified for a 7-year section (Fig. 8). Both skeletal and powder intensities are considerably lower than MAS1, a core strongly affected by soil runoff (Fig. 6). Crushed samples from STM2 show no annual cycles and little variance, unlike the intensities in the intact core (Fig. 8). Removal of the density and architecture by crushing yields a low and stable intensity signal in the green domain without any trend, as opposed to the intact core which shows a declining luminescence intensity trend towards the core top.
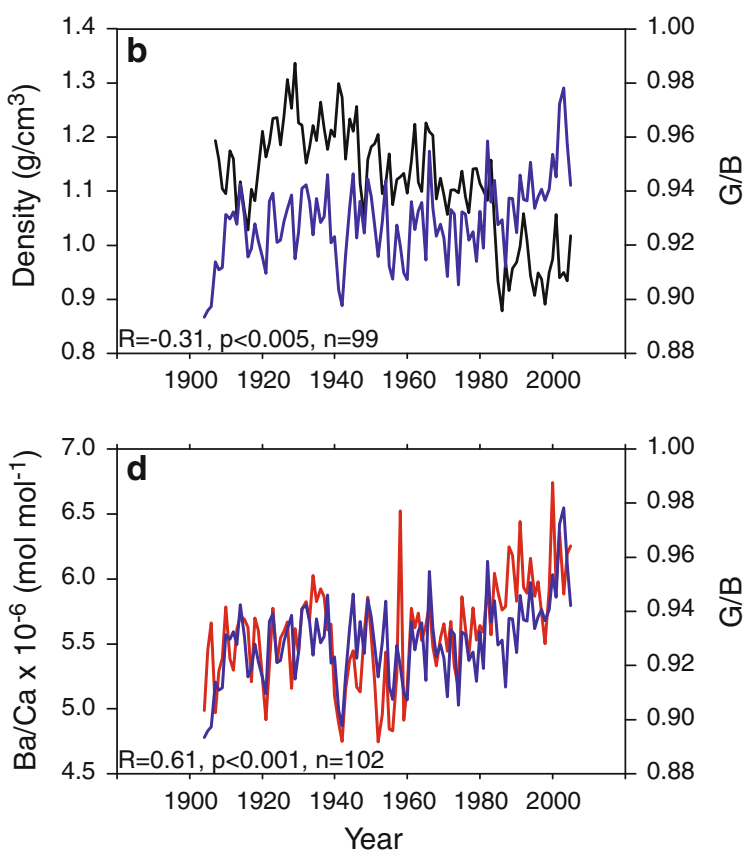

graph; luminescence intensity vs. density (a), density vs. G/B (b), luminescence intensity vs. $\mathrm{Ba} / \mathrm{Ca}(\mathbf{c})$ and $\mathrm{Ba} / \mathrm{Ca}$ vs. $\mathrm{G} / \mathrm{B}(\mathbf{d})$. Note the highly significant annual mean correlation of $\mathrm{G} / \mathrm{B}$ with $\mathrm{Ba} / \mathrm{Ca}$ and $\mathrm{G}$ with density, while negative correlations exist for $\mathrm{G} / \mathrm{B}$ with density and $\mathrm{G}$ with $\mathrm{Ba} / \mathrm{Ca}$

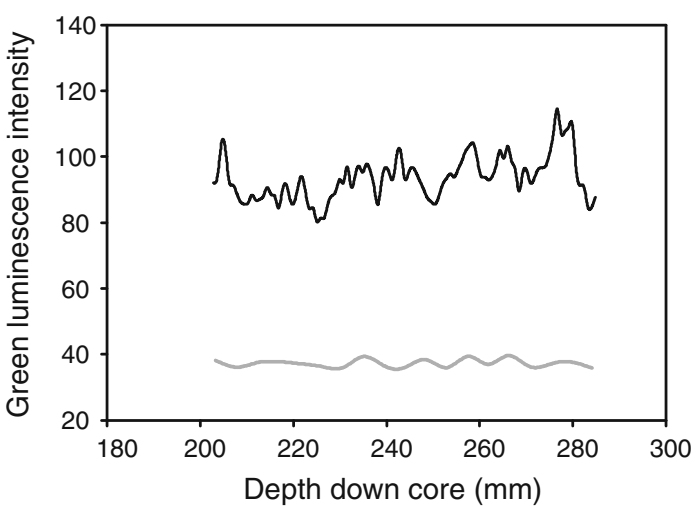

Fig. 8 A 14-point moving average applied to $\mathrm{G}$ data (black), corresponding to a 7-year section (measuring $80 \mathrm{~mm}$ ) from the coral core STM2. The core shows weak annual banding with relatively low amplitudes. By powdering and compressing monthly sections of the coral, we physically removed the architecture. Pellets were then scanned to analyse luminescence intensities (grey), showing little variance and low relative intensities

Declining luminescence intensities were observed for all three long corals from the Antongil Bay region (Fig. 9a), in concert with declining density (e.g., MAS1; Fig. 7). The decreasing trends over the period 1905-2006 in both luminescence intensities $\left(-40.92 / 100\right.$ years; $r^{2}=0.42, P<$ $0.001)$ and density $\left(-0.24 \mathrm{~g} / \mathrm{cm}^{3} / 100\right.$ years; $r^{2}=0.30$, 
Fig. 9 Luminescence intensities are shown in the green spectrum $(\mathrm{G})$ for the three cores MAS1 (red), MAS3 (blue) and ANDRA (green). An observed decline from approximately 1950 is followed by a further sharp decline from 1980 till present (a). G/B spectral luminescence ratios reveal an observed increase since 1980 (b). A long-term comparison of $\mathrm{G} / \mathrm{B}(\mathrm{red})$ and $\mathrm{Ba} / \mathrm{Ca}$ (black) is shown for the core MAS1 (c). G/B ratios and $\mathrm{Ba} / \mathrm{Ca}$ show a good match (see Fig. 7 for correlations) for longterm trends and inter-annual variability. All data were normalised and smoothed using a 21-month filter

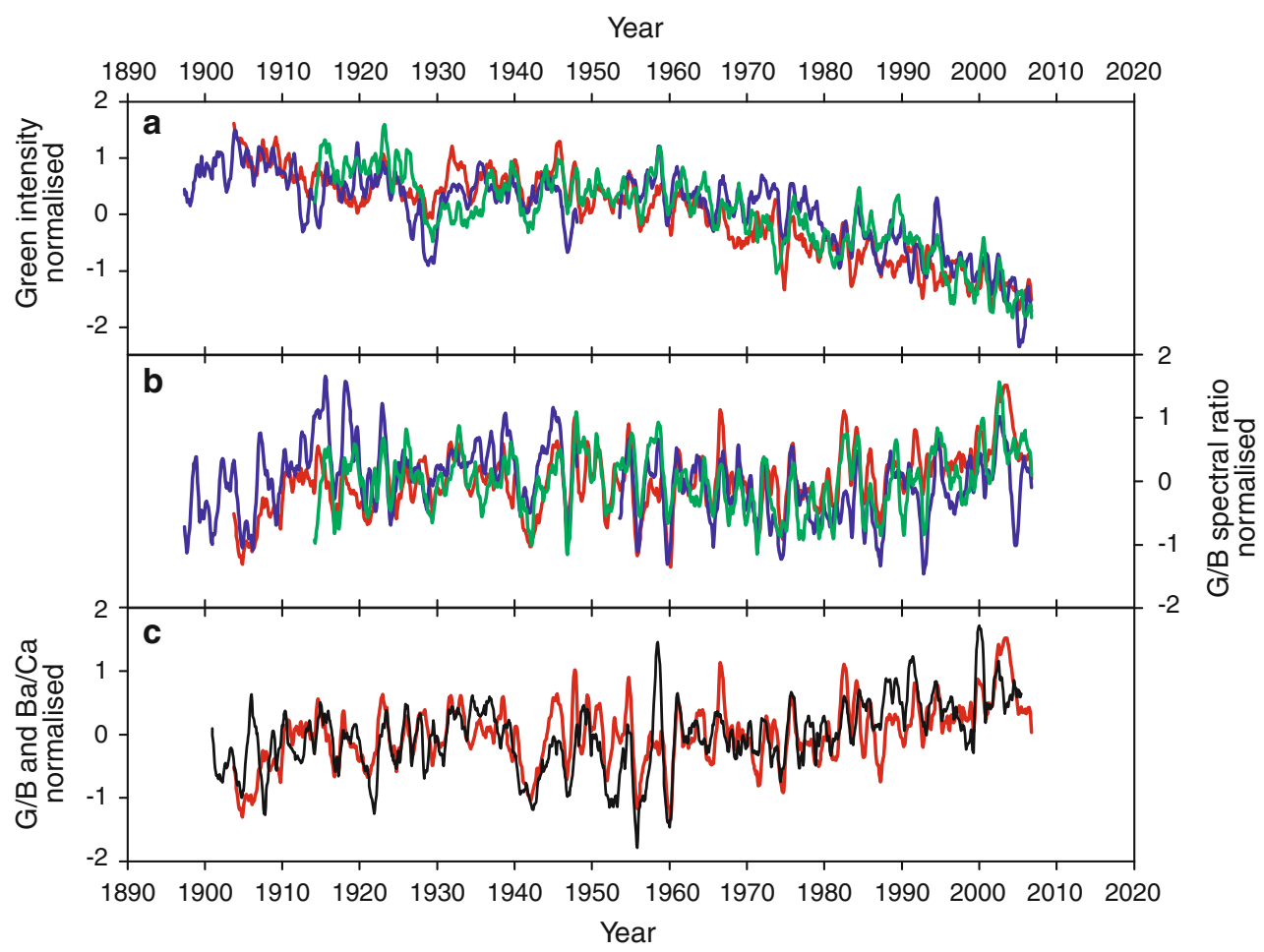

$P<0.001)$ are statistically significant. Both show an accelerated decline since the 1950s. The decreasing trend over the period 1950-2006 in luminescence intensity and density is $-33.77\left(r^{2}=0.37, P<0.001\right)$ and $-0.26 \mathrm{~g} / \mathrm{cm}^{3}$ $\left(r^{2}=0.37, P<0.001\right)$, respectively. Thus, the declining trends are most apparent after the 1950s. By contrast, spectral luminescence ratios show a different long-term pattern with significant increases since approximately 1980 (Fig. 9b). For the MAS1 core, the long-term trends in G/B and $\mathrm{Ba} / \mathrm{Ca}$ ratios correlate well, indicating a modern increase in humic acid and sediment runoff, respectively, in northeast Madagascar (Figs. 9c, 7). As a corollary, G is negatively correlated with $\mathrm{Ba} / \mathrm{Ca}$ and positively correlated with density (Fig. 7). Correlations of MAS1 and MAS3 annual average $\mathrm{G} / \mathrm{B}$ are statistically significant $(R=0.62$, $P<0.001, n=102)$ and higher than $\mathrm{G}(R=0.44$, $P<0.001, n=102)$, again testifying that $\mathrm{G} / \mathrm{B}$ identifies an environmental signal of regional significance.

To validate the G/B ratio in coral MAS1, results are compared against precipitation data from the nearest weather station (WMO code 67095$)$ in Tamatave $\left(18.15^{\circ} \mathrm{S}\right.$, $49.37^{\circ} \mathrm{E}$ ) which yields the most continuous rainfall time series available for northeast Madagascar for the period 1889-1985 (http://www.ncdc.noaa.gov/oa/climate/ghcnmonthly/). MAS1 is used since this coral is influenced by the largest watershed. Annual means were computed for September to August (water year) rainfall and G/B ratios (Fig. 10). As a tracer of humic acid runoff, G/B ratios track the interannual and decadal variability in Tamatave rainfall,
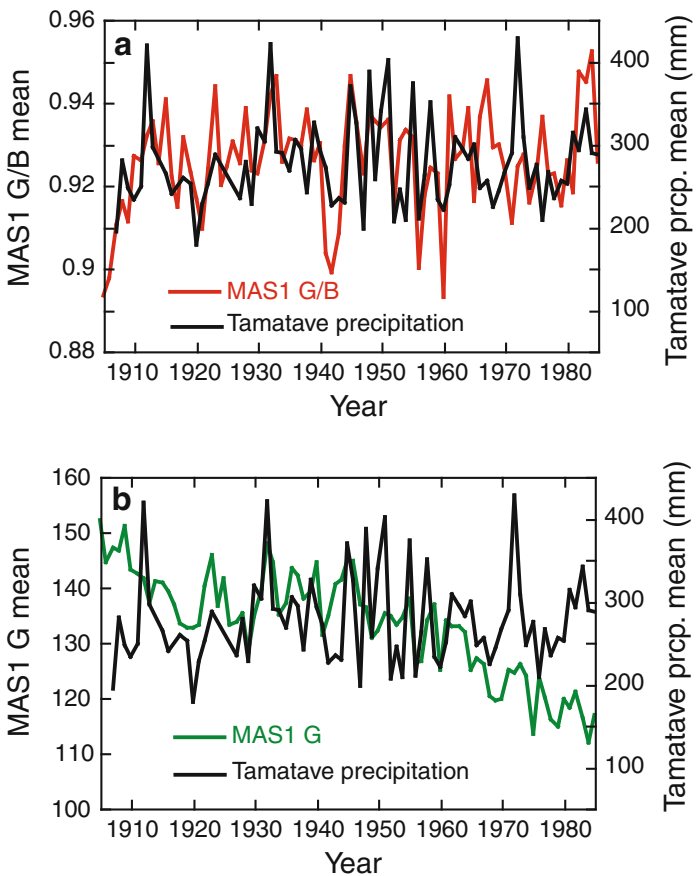

Fig. 10 A comparison of annual mean $G / B$ (a) and $G$ (b) with precipitation data from Tamatave; the most continuous rainfall time series for northeast Madagascar (WMO code $67095 ; 18.15^{\circ} \mathrm{S}$, $49.37^{\circ} \mathrm{E}$ ) covering the period $1905-1985$ (data available at http://www.ncdc.noaa.gov/oa/climate/ghen-monthly/). Annual means were calculated by averaging 'water year' monthly values, September to August. The correlation between MAS1 G/B and rainfall (a) is statistically significant $(R=0.30, P=0.01, n=74)$. There is no significant correlation between MAS1 $\mathrm{G}$ and rainfall $(R=0.01$, $P=0.98, n=74 ; \mathbf{b})$ 
which have a statistically significant correlation $(R=0.30$, $P=0.01, n=74$; Fig. 10). No significant correlation was observed between $\mathrm{G}$ and rainfall $(R=0.003, P=0.98$, $n=74$; Fig. 10), further testifying that G/B ratios are a true measure of humic acid runoff and not overprinted by coral density effects.

\section{Discussion}

The coral skeleton is a complex structure reflecting seasonal and long-term changes in growth. The principle component of the aragonite skeleton is $\mathrm{CaCO}_{3}$, and therefore quantification of geochemical proxies has been achieved by normalising the tracer element to calcium, e.g., $\mathrm{Sr} / \mathrm{Ca}, \mathrm{Ba} / \mathrm{Ca}$ (Alibert et al. 2003; McCulloch et al. 2003). Our results show that spectral luminescence ratios $(\mathrm{G} / \mathrm{B}$ ratios) offer a quantified signal of humic acid incorporation (Isdale 1984; Susic and Boto 1989; Susic et al. 1991; Matthews et al. 1996; Isdale et al. 1998; Wild et al. 2000) when normalised against density (Barnes and Taylor 2001a, b, 2005). The coral aragonite and humic acids it incorporates are both luminescent and have emissions in the green-blue domain (Matthews et al. 1996; Ramseyer et al. 1997; Wild et al. 2000; Nyberg 2002; Sierra et al. 2005). As humic acid emissions have slightly longer wavelengths than aragonite (Ramseyer et al. 1997), dull and bright luminescent intensity bands in coral skeletons have often been referred to as blue and yellow-green bands, respectively (Matthews et al. 1996; Wild et al. 2000).

SLS separates the humic acid signal from the density signal by normalising two grouped intensity values in the green and the blue domain, rather than extracting the humic acid wavelength emission from the skeleton using traditional fluorescence spectroscopy (Matthews et al. 1996; Wild et al. 2000). Although part of the humic acid signal will reside in the blue domain and part of the aragonite signal in the green (and vice versa), it is the relative increase in one compared to the other that reflects compositional changes. Indeed, Wild et al. (2000) divided the spectral emission matrix of a bright band by a dull band and found enhanced bright band emissions at longer wavelengths in ratios between 0.9 and 1.25 , a range replicated by the G/B ratio. Following up from Wild et al. (2000), compositional changes are quantified by SLS, thus providing a means to reconstruct humic acid runoff at a linear resolution of $71.4 \mu \mathrm{m}$. The $\mathrm{G} / \mathrm{B}$ ratio therefore renders a normalised humic acid signal equivalent to a humic acid/aragonite ratio, which is comparable to the geochemical trace element/Ca proxies. Spectral ratios provide more accurate measurements than luminescence intensities for identifying changes in humic acid runoff/erosion within tropical marine environments by normalising for the effects of skeletal density and architecture.

The majority of techniques employed to reconstruct humic acid runoff from coral luminescence have previously focused on intensities alone (Boto and Isdale 1985; Matthews et al. 1996; Isdale et al. 1998; Wild et al. 2000; Barnes and Taylor 2001a). Corals produce high and low annual density bands; consequently conventional luminescence intensity measurements result in an indirect density measurement as proven by SLS (Fig. 7). High concentrations of humic acids locked into a low density $\left(\mathrm{g} / \mathrm{cm}^{3}\right)$ section of coral skeleton would result in a weak luminescence intensity signal, as the area measured is significantly porous. In this situation, both green and blue intensities will be low while the G/B ratio will be relatively high, given the high proportion of humic acids locked within the aragonite. This may explain the occurrence of 'anomalous barium peaks' in coral records, i.e., that are not matched by a similar peak in luminescence intensities (Sinclair 2005). Indeed, for a similar anomaly found in our Madagascar cores for the year 2000, spectral ratios now identify that the 'anomalous barium spike' was caused by an extreme runoff event, rather than caused by any of the multiple biological mechanisms inferred by Sinclair (2005). It coincides with the landfall of Tropical Cyclone Hudah, which caused massive destruction in and around Antongil Bay, and catastrophic sediment and humic acid runoff (Birkinshaw and Randrianjanahary 2007). Consequently, spectral ratios rather than luminescence intensities should be taken to reconstruct humic acid runoff. Luminescence intensity profiles remain important, however, for the construction of age models by counting bands down-core and connecting corresponding marker points (Hendy et al. 2003). Cores possessing individual luminescence intensity traits are likely created by localised intra- and inter-colony variability in density (Felis et al. 2003; Suzuki et al. 2005). Spectral ratios remove this inter-colony variability in density, reflecting predominantly the regional humic acid runoff.

In tropical catchments influencing the Great Barrier Reef, seasonal variability in rainfall was shown to control river flow (Finlayson and McMahon 1988; Furnas and Mitchell 2001). For Madagascar, river discharge time series are extremely scarce hindering further calibration of coral luminescence other than by rainfall data from the nearest weather station Tamatave. The MAS1 time series shows a statistically significant correlation between G/B ratios and Tamatave rainfall for September to August annual means (Fig. 10). The coral G/B time series tracks the interannual to decadal variability in Tamatave rainfall rather well and adds confidence to our results. The relatively low correlation coefficient $(R=0.30, P=0.01$, $n=74$ ) most probably results from Tamatave rainfall not 
precisely replicating the local rainfall variability of the Antainambalana river catchment influencing coral MAS1. However, the green luminescence intensity shows no correlation with rainfall testifying that spectral ratios are the more reliable proxy for river flow carrying soil-derived humic acids. Hydrological modelling of river discharge including gridded rainfall products and land-use change data are still required to calibrate spectral ratios for reconstructing river discharge.

Corals far from terrestrial inputs exhibit dull luminescent bands resulting from the high- and low-density aragonite structure (Barnes and Taylor 2001a; Barnes and Taylor 2005). Skeletal pores can amplify or quench luminescence intensities (Barnes and Taylor 2001a). Indeed, by removing the architecture through crushing left little variance in the baseline signal of aragonite (Fig. 8). Since corals devoid of terrestrial inputs only carry a single luminophore (aragonite), internal light reflections caused by the complex skeletal architecture create fluctuating G/B signals, rather than the uniform response from humic acid runoff. Estuarine corals affected by humic acids possess two luminophores normalised by applying G/B spectral ratios. Internal reflections therefore cause both humic acid and aragonite G/B signal to shift in proportion to one another but do not affect the significant correlation between $\mathrm{G} / \mathrm{B}$ and $\mathrm{Ba} / \mathrm{Ca}$.

As density also affects luminescence intensity, longterm declining luminescence trends are likely a result of common declining coral densities (De'ath et al. 2009). Since the 1950s, luminescence intensity and density both declined in all the Madagascar cores, and correlations are statistically significant as exemplified for the coral core MAS1. Spectral luminescence ratios combined with longterm $\mathrm{Ba} / \mathrm{Ca}$ now confirm the role of density by revealing similar trends, resolving the question as to what causes the marked decline in luminescence intensities shown by some coral luminescence records (Isdale et al. 1998; Cobb et al. 2008; Lough JM pers comm); e.g., 14 out of 20 coral cores sampled from inshore reefs from the Great Barrier Reef display a significant declining luminescence intensity trend (Lough JM pers comm).

In conclusion, declining density trends are responsible for the marked decrease in absolute luminescence intensities rather than humic acid runoff. Indeed, Barnes and Taylor (2005) found that chemical reduction in skeletal density caused a decline in luminescence intensities. Declining luminescence trends has likely affected the interpretation of past erosion records. Nyberg et al. (2007) show multiple cores with declining luminescence intensity trends, which they relate to a decreasing trend in hurricane activity. The findings presented here suggest that such declining trends may alternatively reflect declining coral densities, perhaps in response to the same cause.
Wild et al. (2000) highlighted the importance of comparing neighbouring bright and dull bands to normalise for varying background luminescence which we now relate to changing aragonite density. A method designed to account for the declining luminescence trends is currently being developed, subtracting annual luminescence minimum intensity from the maximum intensity to calculate the annual range (Lough $\mathrm{JM}$ pers comm). All luminescence intensity records from NE Madagascar show declining trends, but when spectral ratios are applied they reveal that soil-derived humic acid runoff increased as opposed to decreased. This could be related to either increases in precipitation or land-use activity both promoting soil erosion and extracting humic acids from the watershed (Fig. 9). Based on this new understanding of coral luminescence, spectral luminescence ratios are proposed as a novel robust proxy for humic acid runoff as recorded by inshore corals, improving on the uncertainties of climate interpretation as addressed by Cobb et al. (2008). In summary, (1) both humic acids and aragonite density determine luminescence intensities in corals and (2) normalisation is required for their deconvolution in order to reconstruct river runoff accurately.

Soil erosion is a major problem in developing countries, with a number of amplifying factors such as land development, cyclone impact and increased seasonal rainfall patterns associated with the monsoon. Coral reefs are presently in a vulnerable state, with increasing sedimentation rates reducing photosynthetic activity of their endosymbiotic algae (Anthony and Connolly 2004). Accurate long-term records of erosion can identify changing rates over time, which coupled with other proxies will assist in identifying potential causes, whether climatic (rainfall) or anthropogenic (land-use change). Spectral luminescence ratios of massive corals can provide such records for tropical marine catchments, identifying where and when runoff is changing. As humic acids are not significantly affected by biological activity within the marine system, high-resolution spectral luminescence ratios provide a reliable proxy for humic acid runoff related to changes in hinterland precipitation and soil erosion. On a local scale, multiple coral core records should identify locations most influenced by changing runoff and erosion into inshore reef systems, e.g., by deforestation. Prior to any future development plans to specific regions, SLS may be considered to assess potential environmental impacts. SLS offers a rapid continuous and cost-effective monitor of river discharge, providing valuable information that will assist in reef conservation efforts and understanding past climate change.

Acknowledgments This work was supported as part of the SINDOCOM and EKP grant under the Dutch NWO program 'Climate 
Variability', grant 854.00034/035, WOTRO 07.55.2004.028 and Australian Research Council Centre of Excellence in Coral Reef Studies. We thank all involved in the development of the UV corescanner, especially Aad Vaars and Sjerry van der Gaast of Avaatech, Rineke Gieles and Thomas Richter from the Marine Geology department at NIOZ, and Stephanie Verbeek from Vrije Universiteit Amsterdam, as well as Edwin Keijzer and Herman Boekel from the Engineering department at NIOZ. We thank the Wildlife Conservation Society (WCS) Madagasacar, especially Bemahafaly Randriamanantsoa, Heriliala Randriamahazo and the WCS/ANGAP team in Maroantsetra, for support in fieldwork logistics and in the organisation of the research permits. We like to thank CAF/CORE Madagascar for granting the CITES permit. We finally would like to thank the reviewers and Janice Lough for their professional and scientific advice which greatly improved the manuscript.

Open Access This article is distributed under the terms of the Creative Commons Attribution Noncommercial License which permits any noncommercial use, distribution, and reproduction in any medium, provided the original author(s) and source are credited.

\section{References}

Alibert C, Kinsley L, Fallon S, McCulloch M, Berkelmans R, McAllister F (2003) Source of trace element variability in Great Barrier Reef corals affected by Burdekin flood plumes. Geochim Cosmochim Acta 67:231-246

Anthony KRN, Connolly SR (2004) Environmental limits to growth: physiological niche boundaries of corals along turbidity-light gradients. Oecologia 141:373-384

Barnes DJ, Taylor RB (2001a) On the nature and causes of luminescent lines and bands in coral skeletons. Coral Reefs 19:221-230

Barnes DJ, Taylor RB (2001b) Natural and artificial luminescence in a skeletal slice of Porites. Coral Reefs 19:270

Barnes DJ, Taylor RB (2005) On the nature and causes of luminescent lines and bands in coral skeletons: II. Contribution of skeletal crystals. J Exp Mar Biol Ecol 322:135-142

Barnes DJ, Taylor RB, Lough JM (2003) Measurement of luminescence in coral skeletons. J Exp Mar Biol Ecol 295:91-106

Birkinshaw C, Randrianjanahary M (2007) The effects of Cyclone Hudah on the forest of Masoala Peninsula, Madagascar. Madagascar Conservation \& Development 2:17-20

Boiseau M, Juillet-Leclerc A (1997) $\mathrm{H}_{2} \mathrm{O}_{2}$ treatment of recent coral aragonite: oxygen and carbon isotopic implications. Chem Geol 143:171-180

Boto K, Isdale P (1985) Fluorescent bands in massive corals result from terrestrial fulvic-acid inputs to nearshore zone. Nature 315:396-397

Carricart-Ganivet JP, Lough JM, Bames DJ (2007) Growth and luminescence characteristics in skeletons of massive Porites from a depth gradient in the central Great Barrier Reef. J Exp Mar Biol Ecol 351:27-36

Cobb K, Cole J, Lough J, Tudhope S (2008) Annually-banded corals as climate proxies. 'White Paper' for PAGES meeting (Trieste), 9-11 June 2008, http://www.pages-igbp.org/cgi-bin/WebObjects/ products. $\mathrm{woa} / \mathrm{wa} /$ product $\mathrm{id}=326$

Corrège T (2006) Sea surface temperature and salinity reconstructions from coral geochemical tracers. Palaeogeogr Palaeoclimatol Palaeoecol 232:408-428

De'ath G, Lough JM, Fabricius KE (2009) Declining coral calcification on the Great Barrier Reef. Science 323:116-119
Dewar RE, Wallis JR (1999) Geographical patterning of interannual rainfall variability in the tropics and near tropics: An L-moments approach. J Climate 12:3457-3466

Dewar RE, Richard AF (2007) Evolution in the hypervariable environment of Madagascar. Proc Natl Acad Sci USA 104:13723-13727

Fallon SJ, White JC, Mcculloch MT (2002) Porites corals as recorders of mining and environmental impacts: Misima Island, Papua New Guinea. Geochim Cosmochim Acta 66:45-62

Fallon SJ, McCulloch MT, van Woesik R, Sinclair DJ (1999) Corals at their latitudinal limits: laser ablation trace element systematics in Porites from Shirigai Bay, Japan. Earth Planet Sci Lett 172:221-238

Felis T, Pätzold J (2003) In: Wefer G, Lamy F, Mantoura F (eds) Marine science frontiers for Europe. Springer, Berlin, pp 11-27

Felis T, Patzold J, Loya Y (2003) Mean oxygen-isotope signatures in Porites spp. corals: inter-colony variability and correction for extension-rate effects. Coral Reefs 22:328-336

Finlayson BL, McMahon TA (1988) Australia vs. the world: A comparative analysis of streamflow characteristics. In: Warner RF (ed) Fluvialgeomorphology of Australia. Academic Press, San Diego, CA, pp 17-40

Fleitmann D, Dunbar RB, McCulloch MT, Mudelsee M, Vuille M, McClanahan TR, Cole JE, Eggins S (2007) East African soil erosion recorded in a 300 year old coral colony from Kenya. Geophys Res Lett 34. doi:10.1029/2006GL028525

Furnas M, Mitchell A (2001) Runoff of terrestrial sediment and nutrients into the Great Barrier Reef. In: Wolanski E (ed) Oceanographic processes of coral reefs: Physical and biological links in the Great Barrier Reef, edited. CRC Press, Boca Raton, FL, pp 37-51

Grottoli AG, Eakin CM (2007) A review of modern coral d180 and d14C proxy records. Earth-Sci Rev 81:67-91

Grottoli AG, Rodrigues LJ, Matthews KA, Palardy JE, Gibb OT (2005) Pre-treatment effects on coral skeletal delta C-13 and delta O-18. Chem Geol 221:225-242

Grove CA, Nagtegaal R, Scheufen T, Koster B, Zinke J, Brummer GJA (2009) Luminescence banding in tropical coral skeletons quantified using novel whole-core microscanning. Geochim Cosmochim Acta 73:A470

Helmle KP, Kohler KE, Dodge RE (2002) Relative optical densitometry and the Coral X-radiograph Densitometry System: CoralXDS. Presented Poster. Int Soc Reef Studies 2002 European Meeting. Cambridge, England. Sept 4-7

Hendy EJ, Gagan MK, Lough JM (2003) Chronological control of coral records using luminescent lines and evidence for nonstationary ENSO teleconnections in northeast Australia. The Holocene 13:187-199

Isdale P (1984) Fluorescent bands in massive corals record centuries of coastal rainfall. Nature 310:578-579

Isdale PJ, Stewart BJ, Tickle KS, Lough JM (1998) Palaeohydrological variation in a tropical river catchment: a reconstruction using fluorescent bands in corals of the Great Barrier Reef, Australia. Holocene 8:1-8

Jansen JHF, Van Der Gaast SJ, Koster B, Vaars AJ (1998) CORTEX, a shipboard XRF-scanner for element analyses in split sediment cores. Mar Geol 151:143-153

Jones PD, Briffa KR, Osborn TJ, Lough JM, TDv Ommen, Vinther BM, Lutterbacher J, Wahl ER, Zwiers FW, Mann ME, Schmidt GA, Ammann CM, Buckley BM, Cobb KM, Esper J, Goose H, Graham N, Jansen E, Kiefer T, Kull C, Kuettel M, Mosley-Thompson E, Overpeck JT, Riedwyl N, Schulz M, Tudhope AW, Villalba R, Wanner H, Wolff E, Xoplaki E (2009) High-resolution palaeoclimatology of the last millennium: a review of current status and future prospects. The Holocene 19:3-49 
Kremen C (2003) The natural history of Madagascar: The Masoala Peninsula. University of Chicago Press, Chicago, pp 1459-1466

Lough JM (2004) A strategy to improve the contribution of coral data to high-resolution paleoclimatology. Palaeogeogr Palaeoclimatol Palaeoecol 204:115-143

Lough JM (2007) Tropical river flow and rainfall reconstructions from coral luminescence: Great Barrier Reef, Australia. Paleoceanography 22. doi:10.1029/2006PA001377

Lough JM, Barnes DJ, Mcallister FA (2002) Luminescent lines in corals from the Great Barrier Reef provide spatial and temporal records of reefs affected by land runoff. Coral Reefs 21:333-343

Macrae CM, Wilson NC (2008) Luminescence database I-Minerals and materials. Microsc Microanal 14:184-204

Matthews BJH, Jones AC, Theodorou NK, Tudhope AW (1996) Excitation-emission-matrix fluorescence spectroscopy applied to humic acid bands in coral reefs. Mar Chem 55:317-332

McCulloch MT, Gagan MK, Mortimer GE, Chivas AR, Isdale PJ (1994) High resolution $\mathrm{Sr} / \mathrm{Ca}$ and $\delta 180$ coral record from the Great Barrier Reef, Australia, and the 1982-83 El Niño. Geochim Cosmochim Acta 58:2747-2754

McCulloch M, Fallon S, Wyndham T, Hendy E, Lough J, Barnes D (2003) Coral record of increased sediment flux to the inner Great Barrier Reef since European settlement. Nature 421:727-730

Milne PJ, Swart KP (1994) Fibre-optic-based sensing of banded luminescence in corals. Appl Spectrosc 48:1282-1284

Nyberg J (2002) Luminescence intensity in coral skeletons from Mona Island in the Caribbean Sea and its link to precipitation and wind speed. Philos Trans R Soc London Ser A 360:749-766

Nyberg J, Malmgren BA, Winter A, Jury MR, Kilbourne KH, Quinn T (2007) Low Atlantic hurricane activity in the $1970 \mathrm{~s}$ and $1980 \mathrm{~s}$ compared to the past 270 years. Nature 447:698-701

Richter TO, van der Gaast S, Koster B, Vaars A, Gieles R, de Stigter HC, de Haas H, van Weering TCE (2006) The Avaatech XRF Core Scanner: technical description and applications to NE Atlantic sediments. Geological Soc Lon 267:39-50

Ramseyer K, Miano TM, Dorazio V, Wildberger A, Wagner T, Geister J (1997) Nature and origin of organic matter in carbonates from speleothems, marine cements and coral skeletons. Org Geochem 26:361-378

Scoffin TP, Tudhope AW, Brown BE (1989) Fluorescent and skeletal density banding in Porites lutea from Papua New-Guinea and Indonesia. Coral Reefs 7:169-178

Sierra MMD, Giovanela M, Parlanti E, Soriano-Sierra EJ (2005) Fluorescence fingerprint of fulvic and humic acids from varied origins as viewed by single-scan and excitation/emission matrix techniques. Chemosphere 58:715-733

Sinclair DJ (2005) Non-river flood barium signals in the skeletons of corals from coastal Queensland, Australia. Earth Planet Sci Lett 237:354-369

Sinclair DJ, Mcculloch MT (2004) Corals record low mobile barium concentrations in the Burdekin River during the 1974 flood: evidence for limited Ba supply to rivers? Palaeogeogr Palaeoclimatol Palaeoecol 214:155-174

Sinclair DJ, Kinsley LPJ, Mcculloch MT (1998) High resolution analysis of trace elements in corals by laser ablation ICP-MS. Geochim Cosmochim Acta 62:1889-1901

Susic M, Boto KG (1989) High-performance liquid-chromatographic determination of humic-acid in environmental-samples at the nanogram level using fluorescence detection. J Chromatogr 482:175-187

Susic M, Boto K, Isdale P (1991) Fluorescent humic-acid bands in coral skeletons originate from terrestrial runoff. Mar Chem 33:91-104

Suzuki A, Hibino K, Iwase A, Kawahata H (2005) Intercolony variability of skeletal oxygen and carbon isotope signatures of cultured Porites corals: Temperature-controlled experiments. Geochim Cosmochim Acta 69:4453-4462

Watanabe T, Minagawa M, Oba T, Winter A (2001) Pretreatment of coral aragonite for $\mathrm{Mg}$ and $\mathrm{Sr}$ analysis: Implications for coral thermometers. Geochem J 35:265-269

Wild FJ, Jones AC, Tudhope AW (2000) Investigation of luminescent banding in solid coral: the contribution of phosphorescence. Coral Reefs 19:132-140 